\title{
Highly Efficient Biolistic Transformation of Embryogenic Cell Suspensions of Banana Via a Liquid Medium Selection System
}

\author{
Tao Dong and Fang-cheng Bi \\ Institute of Fruit Tree Research, Guangdong Academy of Agricultural \\ Sciences/Key Laboratory of South Subtropical Fruit Biology and Genetic \\ Resource Utilization (Ministry of Agriculture and Rural Affairs)/Guangdong \\ Province Key Laboratory of Tropical and Subtropical Fruit Tree Research, \\ Guangzhou, 510640, China
}

\author{
Yong-hong Huang \\ College of Horticulture, Qingdao Agricultural University, Qingdao 266109, \\ P.R. China
}

\begin{abstract}
Wei-di He, Gui-ming Deng, Hui-jun Gao, Ou Sheng, Chun-yu Li, Qiao-song Yang, Gan-jun Yi, and Chun-hua Hu

Institute of Fruit Tree Research, Guangdong Academy of Agricultural Sciences/Key Laboratory of South Subtropical Fruit Biology and Genetic Resource Utilization (Ministry of Agriculture and Rural Affairs)/Guangdong Province Key Laboratory of Tropical and Subtropical Fruit Tree Research, Guangzhou, 510640, China
\end{abstract}

Additional index words. ECS, embryogenic cells, liquid screening system, Musa, transgenesis

\begin{abstract}
An efficient biolistic transformation system of banana combined with a liquid medium selection system was developed during this study. An embryogenic cell suspension (ECS) of Musa acuminata cv. Baxi (AAA) was bombarded with a particle delivery system. After 7 days of restoring culture in liquid M2 medium, embryogenic cells were transferred to a liquid selection $\mathrm{M} 2$ medium supplemented with $10 \mu \mathrm{g} / \mathrm{mL}$ hygromycin for resistance screening. The untransformed cell clusters were inhibited or killed, and a small number of transformants proliferated in the liquid selection medium. After the 0th, first, second, and third generation of antibiotic screening, there were $0,65,212$, and 320 , respectively, vitalityresistant buds obtained from a $0.5-\mathrm{mL}$ packed cell volume (PCV) of embryogenic cell suspension. The $\beta$-glucuronidase (GUS) staining, polymerase chain reaction (PCR) analysis, and Southern blot hybridization results all demonstrated a $100 \%$ positive rate of regenerated resistant seedlings. Interestingly, the number of buds obtained through third-generation screening was almost equal to that obtained from the original ECS in M2 medium without antibiotics. These results suggested that the liquid medium selection system facilitated the proliferation of a positive transgenic ECS, which significantly improved the regeneration rate of transformants. This protocol is suitable for the genetic transformation of all banana genotypes and is highly advantageous to varieties with low callusing potential.
\end{abstract}

Received for publication 24 Jan. 2020. Accepted for publication $20 \mathrm{Feb} .2020$.

Published online 9 April 2020.

This research was supported by the National Key Research and Development Project (2019YFD1000901), the National Natural Science Fund of China (31772267, 31471864), the Project of Science and Technology of Guangzhou (201707010154, 201904020033), the Guangdong Province Science and Technology Plan Project (2018B020202005), and the Common Technical Innovation Team of Guangdong Province on Preservation and Logistics of Agricultural Products (2019KJ145).

T.D. and F.-c.B. contributed equally to this work. C.H. is the corresponding author. E-mail: huchunhua 007@126.com.

This is an open access article distributed under the CC BY-NC-ND license (https://creativecommons. org/licenses/by-nc-nd/4.0/).
Banana (Musa spp.) is an indispensable staple food and nutritional fruit worldwide, and it is one of the most important commercial crops in tropical and subtropical developing countries. However, the development of new banana varieties through conventional breeding is severely hampered because of the long life cycle, sterility, and polyploidy of most cultivated varieties (Khanna et al., 2004). The development of genetic transformation in recent decades may be able to overcome these shortcomings and offer an alternative approach to developing new banana varieties. However, the low transformation rates and low regeneration rates of transformants are the most commonly reported problems in the molecular breeding of banana (Shivani and Tiwari, 2019). Therefore, the establishment of an efficient transformation protocol is crucial for banana genetic improvement.

In preliminary studies, the explant materials used for genetic transformation of banana were multiple bud clumps (Acereto-Escoffié et al., 2005; Maziah et al., 2007; Yip et al., 2011), multiple shoot clumps (Rustagi et al., 2016), apical shoot tips (Tripathi et al., 2005), intercalary meristematic tissues (Tripathi et al., 2008), and ECS (Ganapathi et al., 2001; Ghosh et al., 2009; Hu et al., 2013; Huang et al., 2007). Among these, ECS are the ideal explant because they are unicellular in origin, resulting in the production of stable nonchimeric plants for transgenic work (Sági et al., 2000). Various genetic transformation methods have been developed, such as electric shock (Sagi et al., 1994), biolistic bombardment transformation (Becker et al., 2000; Chee et al., 2005; Daniels et al., 2018; Sági et al., 1995; Vishnevetsky et al., 2011), Agrobacteriummediated transformation (Ganapathi et al., 2001; Ghag et al., 2012; Ghosh et al., 2009; Hu et al., 2013; Huang et al., 2007; Khanna et al., 2004; Kovács et al., 2013; May et al., 1995; Remy et al., 2005; Shivani and Tiwari, 2019), and biolistic bombardment combined with Agrobacterium-mediated transformation (Liu et al., 2017). At present, genetic transformation of Agrobacterium-mediated ECS is the most widely used protocol because the problem of material browning during the transgenic period is abrogated by coculturing in a liquid medium, which significantly improves the yield of transgenic bananas (Ghosh et al., 2009; Huang et a1., 2007). Although the problem of the low transformation rate in the process of banana genetic transformation has been overcome by this method, the regeneration rate of transformants is severely impaired by Agrobacterium-mediated transformation manipulation compared with that of ECS without transgenic treatment.

$\mathrm{Hu}$ et al. (2013) described an efficient protocol using a liquid medium selection system for Agrobacterium-mediated transformation in banana Furenzhi (Musa spp. AA group) (Hu et al., 2013). The transformants obtained in the liquid coculture phase quickly proliferate in the liquid selection medium, whereas nontransformed cells are killed. By taking advantage of this method, many positive transgenic ECS are obtained during a short time, which further improves the amount of transgenic plants obtained. However, the regeneration rate of transformants remains the same. In addition, it is not easy to inhibit the growth of Agrobacterium in liquid medium during the screening process, which leads to the failure of the entire experiment, especially for novice researchers. Therefore, improving the regeneration efficiency of transformants offers a great alternative approach to improving the transgenic efficiency of bananas. To address this challenge, in the present study, a biolistic transformation system combined with a liquid medium selection system was used to deliver plasmids to establish an efficient genetic transformation system in ECS of Musa acuminata cv. Baxi. 
Table 1. Composition of media used in this study.

\begin{tabular}{|c|c|c|}
\hline Medium & Composition & Functions \\
\hline$\overline{\mathrm{M} 2}$ & $\begin{array}{l}{ }^{\mathrm{z}} \text { MS basal medium, } 1 \mathrm{mg} / \mathrm{mL} 2,4-\mathrm{D}, 1 \mathrm{mg} / \mathrm{L} \text { biotin, } 100 \mathrm{mg} / \mathrm{L} \text { malt extract, } 100 \mathrm{mg} / \mathrm{L} \\
\text { glutamine, } 45 \mathrm{~g} / \mathrm{L} \text { sucrose, } \mathrm{pH} 5.3\end{array}$ & Initiation and maintenance of ECS \\
\hline M3 & $\begin{array}{l}{ }^{\mathrm{z}} \mathrm{MS} \text { basal medium, } 1 \mathrm{mg} / \mathrm{L} \text { biotin, } 100 \mathrm{mg} / \mathrm{L} \text { glutamine, } 100 \mathrm{mg} / \mathrm{L} \text { malt extract, } 0.2 \mathrm{mg} / \mathrm{L} \\
\alpha \text {-naphthaleneacetic acid, } 0.1 \mathrm{mg} / \mathrm{L} \text { kinetin, } 45 \mathrm{~g} / \mathrm{L} \text { sucrose, } 7 \mathrm{~g} / \mathrm{L} \text { agar, } \mathrm{pH} 5.8\end{array}$ & Induction of somatic embryos from ECS \\
\hline M4 & $\begin{array}{l}{ }^{z} \mathrm{MS} \text { basal medium, } 100 \mathrm{mg} / \mathrm{L} \text { glutamine, } 100 \mathrm{mg} / \mathrm{L} \text { malt extract, } 0.1 \mathrm{mg} / \mathrm{L} \\
\text { 6-benzylaminopurine, } 0.2 \mathrm{mg} / \mathrm{L} \text { indoleacetic acid, } 30 \mathrm{~g} / \mathrm{L} \text { sucrose, } 7 \mathrm{~g} / \mathrm{L} \text { agar, } \mathrm{pH} 5.8\end{array}$ & Germination of somatic embryos \\
\hline MR & ${ }^{\mathrm{z}} \mathrm{MS}$ basal medium, $100 \mathrm{mg} / \mathrm{L}$ glutamine, $100 \mathrm{mg} / \mathrm{L}$ malt extract, $30 \mathrm{~g} / \mathrm{L}$ sucrose, $7 \mathrm{~g} / \mathrm{L}$ agar, $\mathrm{pH} 5.8$ & Rooting of shoots \\
\hline
\end{tabular}

${ }^{\mathrm{z}}$ Murashige and Skoog (1962).

$\mathrm{ECS}=$ embryogenic cell suspension.

\section{Materials and Methods}

Experimental materials. ECS of Musa acuminata cv. Baxi were developed from immature male flowers using the previous protocol of $\mathrm{Hu}$ et al. (2013). Suspensions were maintained in liquid M2 medium (Table 1) at $27 \pm 1{ }^{\circ} \mathrm{C}$ in the dark and subcultured every 2 weeks. ECS subcultured for $5 \mathrm{~d}$ were harvested and passed through an $80-\mu \mathrm{m}$ sieve to remove large cell clusters and then centrifuged at $3500 \mathrm{rpm}$ for $10 \mathrm{~min}$. The packed cells were used for transformation experiments. The pCAMBIA1301 plant expression vector was used for transformation. This vector contained the hygromycin resistance gene (Hpt) as the selectable marker and the $\beta$-glucuronidase gene (GUS) as the reporter gene within the T-DNA region.

Biolistic-mediated transformation. PCV embryogenic cells $(0.5 \mathrm{~mL})$ were spread on the center of a petri dish and then bombarded using the Biolistic PDS-1000/He TM System (Bio-Rad, Berkeley, CA). Before bombardment, cells were placed on a petri dish containing M2 medium supplemented with $0.45 \mathrm{M}$ mannitol for $4 \mathrm{~h}$ (Vishnevetsky et al., 2011). The hyperosmolality-treated embryogenic cells were bombarded once with gold particles $(1.0 \mu \mathrm{m}$; Bio-Rad $)$ coated with plasmid DNA (pCAMBIA1301) under a 9-cm firing range at $1300 \mathrm{psi}$ He pressure in a 28 -inch $\mathrm{Hg}$ vacuum (Becker et al., 2000). The bombarded embryogenic cells were placed at $27 \pm 1{ }^{\circ} \mathrm{C}$ overnight for recovery growth.

Resistance screening. In our preliminary studies, we found that $10 \mathrm{mg} / \mathrm{L}$ hygromycin was the optimal antibiotic dose for inhibiting cell growth and subsequent differentiation in the liquid medium selection system (Table 1) (Hu et al., 2013). In this study, the transformation efficiency and embryo induction of the 0th, first, second, and third generation embryogenic cells were detected using GUS staining to identify the optimal generation to attain a high regeneration rate of transformants. After an overnight restoring culture, the bombarded cells were subsequently grown for $7 \mathrm{~d}$ in $\mathrm{M} 2$ medium without antibiotics and were considered the 0th generation. Some of the embryonic cells were transferred to liquid selection medium and incubated in the dark at $27 \pm 1{ }^{\circ} \mathrm{C}$ with shaking at $100 \mathrm{rpm}$ for three generations. The cultures were subcultured once every 3 weeks and were regarded as the first, second, and third generations. Selection was performed in M2 medium supplemented with hygromycin $10 \mathrm{mg} / \mathrm{L}, 10 \mathrm{mg} / \mathrm{L}$, and 5 $\mathrm{mg} / \mathrm{L}$ in the three generations, respectively.
Plant regeneration. To detect the efficiency of the liquid medium selection system, we transferred embryogenic cells screened from the 0th, first, second, and third generations to M3 medium containing $5 \mathrm{mg} / \mathrm{L}$ hygromycin. Cells were cultured in the dark at $27 \pm 1{ }^{\circ} \mathrm{C}$ for 6 to 8 weeks for embryo development. Mature resistant somatic embryos were then transferred to M4 medium and cultured under light/dark (12 h/12 h) conditions for somatic embryo germination. The regenerated buds were transferred to RM medium and cultured under light/dark (12 h/12 h) conditions to obtain complete transformed plants. At the same time, untransformed embryogenic cells were induced and germinated as the control by inoculating in M3 medium without antibiotics until regenerated plants were obtained. The compositions of the media used in this study are shown in Table 1. M3 medium supplemented with 5 $\mathrm{mg} / \mathrm{L}$ hygromycin (SM3 medium) was used for embryo induction, and no hygromycin was supplemented in the shoot induction and rooting medium.

Histochemical GUS assay. GUS staining of samples was conducted according to a previously reported protocol (Jefferson, 1987). ECS, germinated somatic embryos, leaf sections, and root sections from both transformed cultures and corresponding nontransformed cultures (control) were tested.

Identification of transgenic plants. Genomic DNA of samples, including nontransformed controls and hygromycin-resistant plantlets, was isolated using an improved $\mathrm{CTAB}$ method (Hu et al., 2013). A pair of specific primers (P1，5'-GACGATTGCGTCGCATCGAC-3'; P2, 5' -CGAAAAGTTCGACAGCGTCTCC-3') corresponding to the 844-bp fragment of the $\mathrm{Hyg}$ coding region was designed to identify positive transformants. The primers were synthesized by Sangon Biotech Co., Ltd. (Shanghai, China), and sample DNA (50 ng) was used as the polymerase chain reaction (PCR) template. PCR analysis was performed in a programmed temperature control system (Biometra, Göttingen, Germany). The reaction conditions were as follows: $94{ }^{\circ} \mathrm{C}$ for $3 \mathrm{~min}, 32$ cycles of $94^{\circ} \mathrm{C}$ for $15 \mathrm{~s}, 58^{\circ} \mathrm{C}$ for $30 \mathrm{~s}$, and $72{ }^{\circ} \mathrm{C}$ for $1.5 \mathrm{~min}$. Amplified PCR products were analyzed by electrophoresis in $1.0 \%(\mathrm{w} / \mathrm{v})$ agarose gels.

For Southern blot analyses, genomic DNA was isolated and digested with the BamHI and XbaI restriction enzymes. Digested DNA was then separated on a $1 \%$ agarose gel and subsequently transferred to a nylon membrane (Hybond-XL; Amersham Pharmacia Biotech, Little Chalfont, UK) (Southern, 1975). Labeling and detection were conducted following the protocol for ECL direct nucleic acid labeling and detection (Amersham Biosciences). DNA fragments containing the $H y g$ gene were amplified from the plasmid with primer 3 $\left(5^{\prime}\right.$-CGTTATGTTTATCGGCACT-3') and primer $4\left(5^{\prime}\right.$-TTGGCGACCTCGTATTGG$\left.3^{\prime}\right)$ and were used as hybridization probes on the Southern blot membrane.

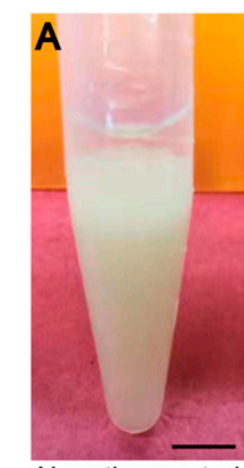

Negative control

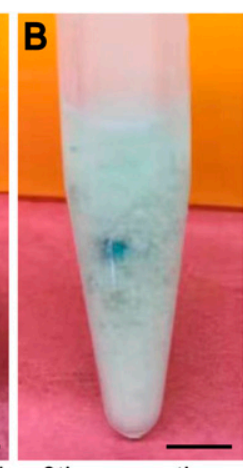

Oth generation

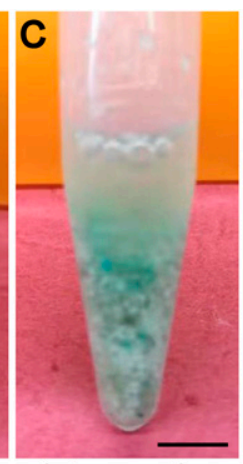

1st generation

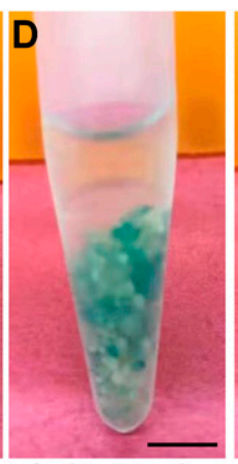

2nd generation

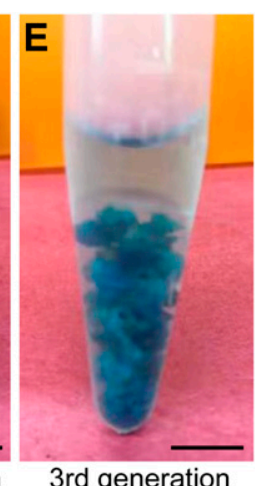

3rd generation

Fig. 1. Histochemical $\beta$-glucuronidase (GUS) assay of banana embryogenic cell suspensions (ECS) at different stages after particle bombardment. The ECS of nontransformed (A) and the 0th (B), first (C), second (D), and third (E) generations of antibiotic screening after particle bombardment were collected to detect the efficiency of the transgene with GUS staining. The results showed that the ratio of positive transformants increased with the length of the liquid medium screening process. The nontransformed ECS was used as a control. Bar $=0.5 \mathrm{~cm}$. 


\section{Results}

Screening efficiency of liquid selection medium after particle bombardment. Embryogenic cells were bombarded and restored in culture for $7 \mathrm{~d}$ (0th generation) in restoration medium. PCV material $(0.2 \mathrm{~mL})$ was taken from each culture dish for GUS staining to detect the efficiency of transformed materials, and the nontransformed materials were used as the negative control. The results showed that positive transgenic cell clusters were detected in all six dishes of bombarded materials (Fig. 1B), but not in the untransformed ECS (Fig. 1A). The minimum and the maximum numbers of positive transgenic cell clusters were 6 and 18, respectively. Some of the embryogenic cells cultured for $7 \mathrm{~d}$ in restoration medium were transferred to liquid selection medium for screening. In the presence of antibiotics, untransformed cells grew slowly and gradually browned and died, whereas transformed cell clusters continuously proliferated. The first, second, and third generations of the screened embryogenic cell suspensions were stained with GUS. The results showed that the positive rate of GUS-like staining increased with increased screening time (Fig. 1C-F). This finding indicated that with increased screening time, the proportion of transformed cells in the medium gradually increased. After three generations of resistance screening, almost all of the embryogenic cells obtained were GUS-like stained. Finally, a well-grown transgenic ECS was obtained.

High regeneration efficiency of transformants after liquid screening culture. To investigate the effects of liquid screening culture on embryo induction after particle bombardment, we transferred $0.5 \mathrm{~mL}$ of PCV of embryogenic cells from the 0th, first, second, and third rounds of screening to M3 medium supplemented with $5 \mathrm{mg} / \mathrm{L}$ hygromycin (SM3 medium). The same volume of embryogenic cells without bombardment on M3 medium and SM3 medium was considered the positive control and negative control, respectively. All embryogenic cells were subcultured once per month. Three months later, many welldeveloped white mature somatic embryos were induced from the positive control cells, but they were not induced from negative control cells (Fig. 2A and B). In addition, Fig. 2C-F shows that the embryogenic cells ( 0 th) grown in restoring culture for $7 \mathrm{~d}$ after bombardment but without undergoing liquid medium selection performed poorly. Moreover, only a few yellow-white embryos were induced on the SM3 medium (Fig. 2C). However, the embryogenic cells treated with the biolistic transformation system combined with resistance screening liquid medium performed much better. At the later stage of embryo induction of the first generation of liquid screening, more yellow-white and a few white mature somatic embryos were scattered among the browning callus (Fig. 2D). The number of embryos obtained from the second generation of liquid screening was more than that from the first generation, and their morphology was more uniform (Fig. 2E). After third-generation screening, the induced embryos had significantly better quality and quantity than those from the first two generations of screening, and they were almost the same as the positive control (Fig. 2F). We performed a histochemical GUS assay on the aforementioned embryos to determine the reliability of the results of the liquid-resistant medium screening. Uniform GUS-like staining was observed in randomly selected hygromycin-resistant embryos (Fig. 2G), but not in untransformed embryos (Fig. 2H).

To investigate the effects of liquid screening culture on embryo germination after particle bombardment, we inoculated mature hygromycin-resistant somatic embryos and control somatic embryos on M4 somatic embryo germination medium. Two weeks later, the control somatic embryos began to germinate; 1 month later, 356 regenerated buds with healthy development were obtained from $0.5 \mathrm{~mL}$ PCV of initial embryogenic cells (Fig. 3A). Nevertheless, the resistant yellow-white embryos from the 0th generation did not regenerate on M4 somatic embryo germination medium due to the poor quality and small number of the
Positive control

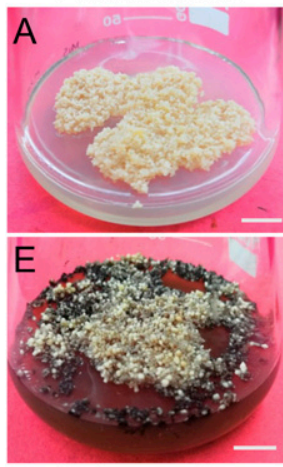

2nd generation
Negative control
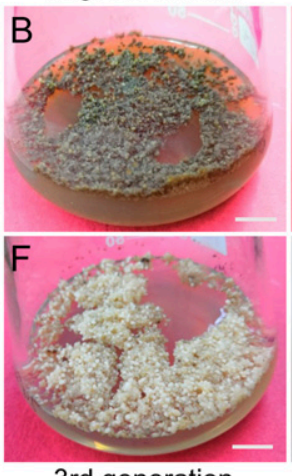

3rd generation embryos. The numbers of usually regenerated buds obtained from $0.5 \mathrm{~mL}$ PCV of the first-generation, second-generation, and third-generation screened callus were 65,212 , and 320, respectively (Fig. 3B-D). The number of resistant buds from the third generation was close to that of the control, which was consistent with the high embryo induction efficiency mentioned. These findings indicate that the liquid medium selection system has little influence on the regeneration efficiency of transformants after par-

Identification of transgenic plants. The combination of the bombardment system and the liquid selection protocol enabled us to obtain GUS-positive embryos. Germinated embryos were transferred to M4 medium for shoot regeneration. The regenerated shoots were transferred to RM medium, and adventitious roots developed in 2 weeks. To detect whether these plantlets were positive transgenics, GUS staining, PCR analysis, and Southern blot hybridization were performed. As shown in Fig. 4A, strong GUS expression and GUS-like staining were detected in leaves and roots from all the putative transformed plants, whereas no GUS activity was detected in leaves and roots from nontransformed control ticle bombardment.

Fig. 2. Embryo induction of embryonic suspension cells after liquid medium screening. Nontransformed ECS induced on M3 medium and SM3 medium was regarded as the positive control (A) and negative control (B), respectively. The ECS from the 0th $(\mathbf{C})$, first $(\mathbf{D})$, second $(\mathbf{E})$, and third $(\mathbf{F})$ generations of antibiotic screening after particle bombardment were transferred to SM3 medium to induce embryos. $\beta$-glucuronidase (GUS) staining analysis of embryos induced from nontransformed (G) and randomly selected hygromycin-resistant embryos induced from liquid screening cells $(\mathbf{H})$. After the third generation of screening, the induced embryos had significantly better quality and quantity than those induced from the first two generations of screening and were almost same as the positive control. Bar= $1 \mathrm{~cm}$ in $\mathbf{A}$ to $\mathbf{F}$. Bar $=0.5 \mathrm{~cm}$ in $\mathbf{G}$ and $\mathbf{H}$.

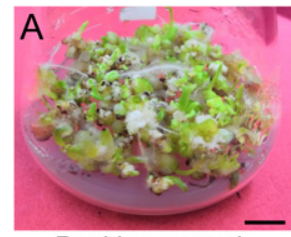

Positive control

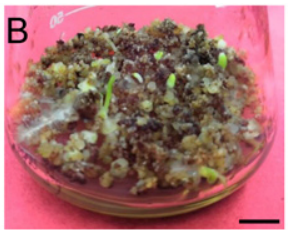

1st generation

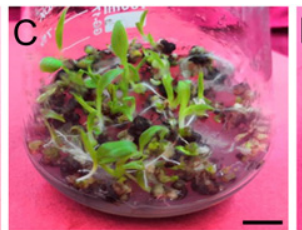

2nd generation

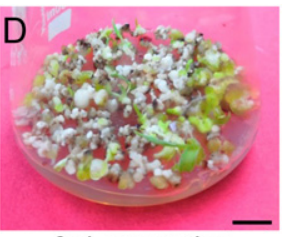

3rd generation
Fig. 3. Germination of embryos after liquid medium screening. Nontransformed embryos were transferred to M4 medium (A) as the positive control. Embryos from the first (B), second (C), and third (D) generations of antibiotic screening after particle bombardment were transferred to M4 medium to detect the germination rate. After the third generation of screening, the buds had significantly better quality and quantity than the first two generations and were almost the same as the positive control. Bar $=1 \mathrm{~cm}$ 
A
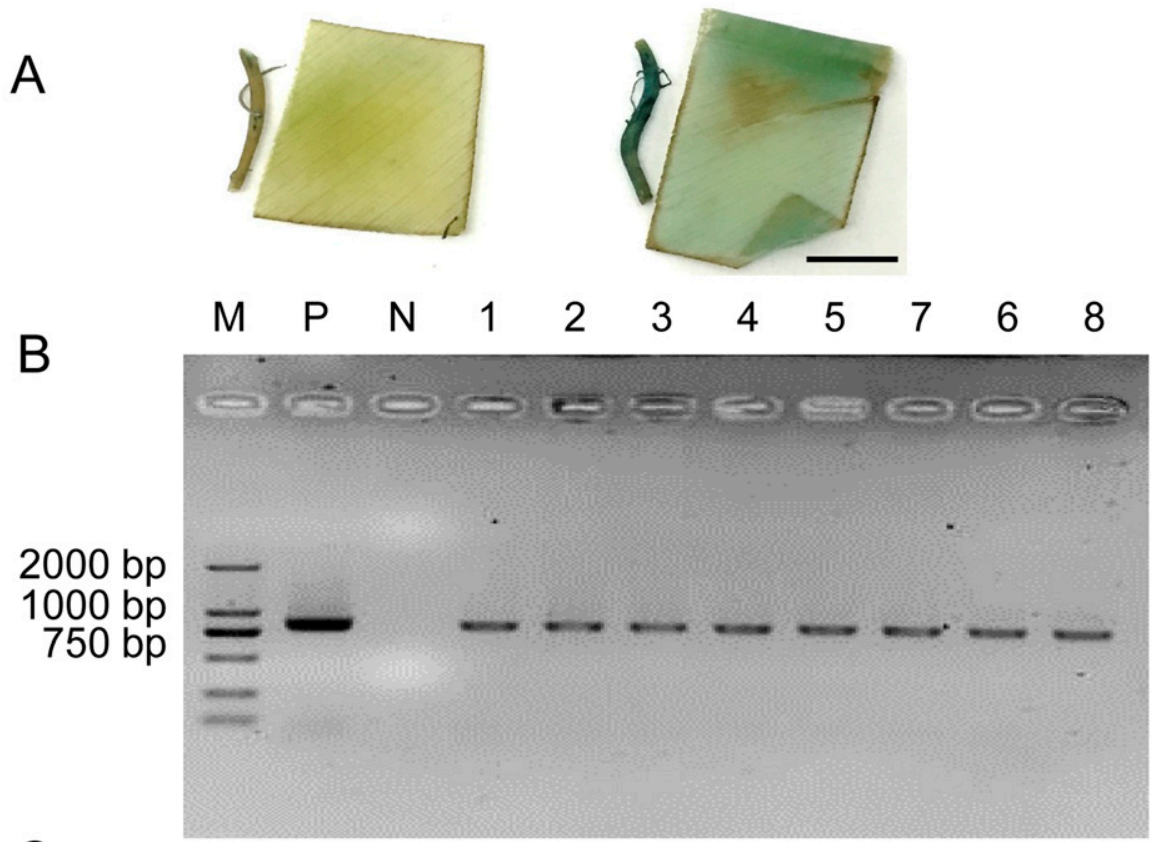

C

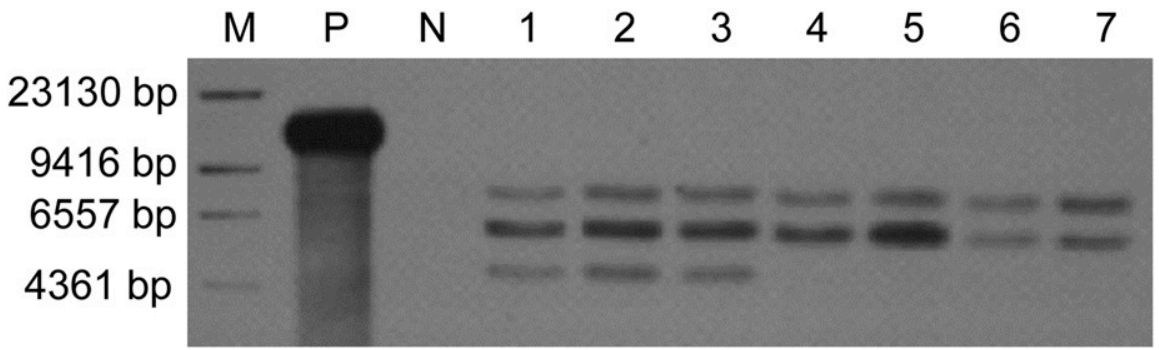

Fig. 4. Identification of transgenic plants by $\beta$-glucuronidase (GUS) staining, polymerase chain reaction analysis, and Southern blot hybridization. (A) GUS staining was observed in leaves and roots from putative transgenic plants, but not from nontransgenic plants. Bar $=1 \mathrm{~cm}$. (B) Bands $(844 \mathrm{bp})$ from the Hyg gene were detected in all putative transgenic plants, but not in nontransformed control plants. (C) All putative transgenic plants had a band hybridized with the $H y g$ probe. All three analyses confirmed that $100 \%$ of the banana plants regenerated under hygromycin selection were positive transgenic plants. $\mathrm{M}$ in lane 1 is a molecular weight marker; $\mathrm{P}$ in lane 2 is the positive control (plasmid pCAMBIA1301 DNA); $\mathrm{N}$ in lane 3 is the negative control (untransformed plants DNA). Lanes 1-7 are samples collected from putative transgenic plants.

plants. PCR showed that 844-bp bands from the Hyg gene were detected in all hygromycinresistant plants, but not in nontransformed control plants (Fig. 4B). PCR and GUS assays indicated stable transformation. To test whether any of the putative transformants had the transgene integrated in the banana genome, seven randomly selected GUS-like stained and PCRpositive plants were subjected to Southern blot analysis (Fig. 4C). Transgenic plants contained two to three bright bands hybridizing with the Hyg probe, whereas nontransgenic plants did not produce any bands. Analysis of the transformed plants confirmed the stable integration of $\mathrm{Hyg}$ into the banana genome. All three analyses confirmed that $100 \%$ of the banana plants regenerated under hygromycin selection were transgenic-positive plants. Furthermore, all transgenic plants developed normally (Fig. 5).

\section{Discussion}

Agrobacterium-mediated transformation of ECS has been widely used but is not irreplaceable. Since the initial banana genetic transformation was established by May et al. (1995), considerable progress has been made in this field during the past few decades. Genetic transformation of banana has been an essential tool for molecular breeding and gene function identification. Until now, transgenic bananas mainly have been produced by particle bombardment and Agrobacterium-mediated transformation of ECS. At present, the Agrobacterium-mediated transformation of ECS is the most widely used method for banana. However, banana is a monocotyledon plant, and the ECS is not easily infected by Agrobacterium. Moreover, the liquid coculture system can effectively solve the problem of material browning during the transgenic process. However, it is easier for Agrobacterium to reproduce, and their reproduction is more challenging to control in this liquid environment. Therefore, it is necessary to add a high concentration of cephalosporin in the subsequent screening process, and it may not be successful, espe- cially for a novice researcher. In addition, the regeneration rate of banana ECS is low, even for Musa acuminata cv. Mas, which has a high embryogenic ability and germination rate of mature somatic embryos of less than $20 \%$ (Wei et al., 2005). Our preliminary work demonstrated that the regeneration rate of transformants mediated by Agrobacterium is severely impaired due to the high concentration of the added cephalosporin, resulting in a low transgenic efficiency (Hu et al., 2013). Therefore, it is necessary to develop an efficient, repeatable, and genotype-independent transformation system by improving the regeneration frequency of transformants.

Establishment of a banana biolistic transformation system combined with a liquid selection medium. A previous study has shown that for most banana cultivars, the efficiency of the ECS transgene mediated by the Agrobacterium is significantly higher than that mediated by biolistic transformation (Arinaitwe et al., 2004). The efficiency of biolistic transformation is severely undervalued because bombarded transformants are directly transferred to semi-solid screening media containing antibiotics to regenerate. A similar situation occurred in the present study. As shown in Fig. 2C, embryogenic cells (0th) restored in culture for $7 \mathrm{~d}$ after bombardment were transferred to somatic embryo induction medium, and no vigorous transgenic embryos were obtained. As for biolistic transformation, a liquid medium is a more effective selection system than a solid medium (Vishnevetsky et al., 2011). However, the disadvantage of this reported liquid selection medium is that the E1based liquid medium is used for embryo development and maturation, resulting in a few positive transgenic plants. In our previous work, we described an improved liquid medium selection system that dramatically improved the efficiency of Agrobacteriummediated transformation ( $\mathrm{Hu}$ et al., 2013). This liquid medium selection system is the M2-based medium, which is mainly used for the maintenance of ECS supplemented with $10 \mathrm{mg} / \mathrm{L}$ hygromycin as the selection pressure. By using this method, the transgenic embryogenic cells used for the induction of embryos can be rapidly propagated, which cannot be achieved by the E1-based liquid selection medium. This method improves the regeneration rate of transformants. To date, the biolistic transformation system of banana via the liquid medium selection system has not been reported. Therefore, it was developed and analyzed in the present study.

This method used biolistics to deliver target plasmids combined with liquid medium screening. As shown in Fig. 1B, the maximum number of positive transgenic cell clusters from each petri dish was 18 , suggesting acceptable initial transformation efficiency by biolistic transformation. The embryogenic cells cultured in the restoring medium for $7 \mathrm{~d}$ were transferred to the liquid selection medium. Under selection pressure of $10 \mu \mathrm{g} / \mathrm{mL}$ hygromycin, untransformed cells grew slowly and gradually browned 


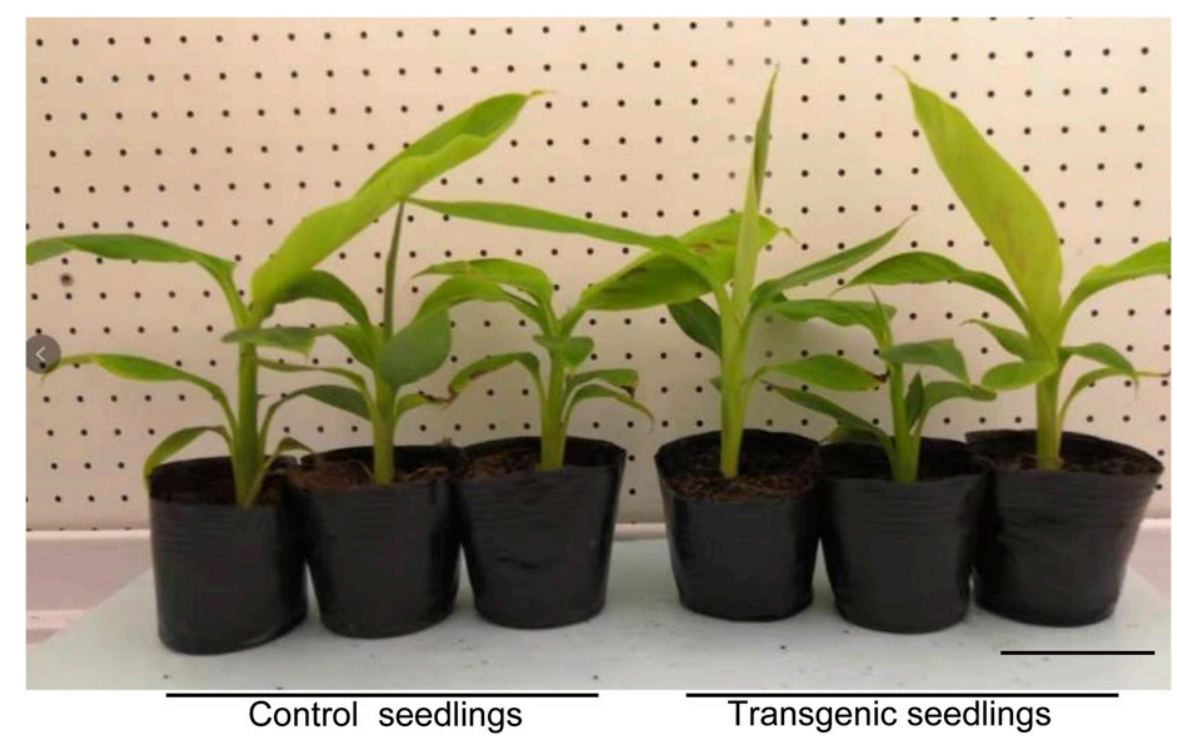

Fig. 5. Transgenic banana plants show healthy growth and development. The left three seedlings are control seedlings, and the right three seedlings are transgenic seedlings. Bar $=10 \mathrm{~cm}$.

and died, whereas transformed cell clusters continuously proliferated. After three generations of resistance screening, almost all embryogenic cells obtained were GUSstained (Fig. 1E). Subsequently, quantities of well-grown transgenic ECS were obtained and transformed on SM3 medium to induce embryos. As shown in Fig. 2, after the third generation of screening, the induced embryos had significantly better quality and quantity than the first two generations and were almost the same as the positive control. Then, the induced embryos were inoculated on M4 medium for somatic embryo germination. Even after one generation of resistance screening, a $0.5-\mathrm{mL}$ packed cell volume of resistant ECS obtained enough resistant regeneration buds. After two or more generations of resistance screening, the numbers of resistant regenerated embryos and buds were further improved. The number of resistant buds from third-generation screening was close to that of the healthy regeneration of the control (Fig. 3). This result was consistent with the high embryo induction efficiency mentioned, which indicated that the liquid medium selection system had little influence on the regeneration efficiency of transformants after particle bombardment. In contrast to previous studies, selection was performed in liquid selection medium supplemented with a stepwise decrease of the hygromycin concentration. The hygromycin concentrations were $10 \mathrm{mg} / \mathrm{L}, 10 \mathrm{mg} / \mathrm{L}$, and $5 \mathrm{mg} / \mathrm{L}$ in the three generations of liquid selection media. At the same time, antibiotics were not added to the embryo germination medium, which eliminated the adverse effects of antibiotics on regeneration and made it easier to obtain regenerated plants. It is worth mentioning that the GUS staining, PCR analysis, and Southern blot hybridization results all demonstrated that the positive rate of regenerated resistant plants was $100 \%$ (Fig. 4). These results suggested that
Chee, W.W., M. Jalil, M.O. Abdullah, R.Y. Othman, and N. Khalid. 2005. Comparison of beta-glucuronidase expression and anatomical localization in bombarded immature embryos of banana cultivar mas via biolistic transformation. Asia Pac. J. Mol. Biol. Biotechnol. 13:15-22.

Daniels, D., R.G. Kosky, and L. Posada-Perez. 2018. Genetic transformation of the banana hybrid cultivar 'FHIA-18' (Musa sp.) via particle bombardment using argon gas. Intl. J. Adv. Scientific Res. Engineering 4:42-48.

Ganapathi, T.R., N.S. Higgs, P.J. Balint-Kurti, C.J. Arntzen, and J.M.V. Eck. 2001. Agrobacteriummediated transformation of embryogenic cell suspensions of the banana cultivar Rasthali (AAB). Plant Cell Rpt. 20:157-162.

Ghag, S.B., U.K.S. Shekhawat, and T.R. Ganapathi. 2012. Petunia floral defensins with unique prodomains as novel candidates for development of fusarium wilt resistance in transgenic banana plants. PLoS One 7:E39557.

Ghosh, A., T.R. Ganapathi, P. Nath, and V.A. Bapat. 2009. Establishment of embryogenic cell suspension cultures and Agrobacteriummediated transformation in an important Cavendish banana cv. Robusta (AAA). Plant Cell Tissue Organ Cult. 97:131-139.

Hu, C.H., Y.R. Wei, Y.H. Huang, and G.J. Yi 2013. An efficient protocol for the production of chit42 transgenic Furenzhi banana (Musa spp. AA group) resistant to Fusarium oxysporum. Vitro Cellular \& Developmental Biology Plant 49:584-592.

Huang, X., X.-L. Huang, W. Xiao, J.-T. Zhao, X.-M. Dai, Y.-F. Chen, and X.-J. Li. 2007. Highly efficient Agrobacterium-mediated transformation of embryogenic cell suspensions of Musa acuminata cv. Mas (AA) via a liquid co-cultivation system. Plant Cell Rpt. 26:1755-1762.

Jefferson, R.A. 1987. Assaying chimeric genes in plants: The GUS gene fusion system. Plant Mol. Biol. Rpt. 5:387-405.

Khanna, H., D. Becker, J. Kleidon, and J. Dale. 2004. Centrifugation assisted Agrobacterium tumefaciens-mediated transformation (CAAT) of embryogenic cell suspensions of banana (Musa spp. Cavendish AAA and Lady finger AAB). Mol. Breed. 14:239-252.

Kovács, G., L. Sági, G. Jacon, G. Arinaitwe, J.-P. Busogoro, E. Thiry, H. Strosse, R. Swennen, and S. Remy. 2013. Expression of a rice chitinase gene in transgenic banana ('Gros Michel', AAA genome group) confers resistance to black leaf streak disease. Transgenic Res. 22:117-130.

\section{Literature Cited}

Acereto-Escoffié, P.O.M., B.H. Chi-Manzanero, S Echeverría-Echeverría, R. Grijalva, A.J. Kay, T. González-Estrada, E. Castaño, and L.C. Rodríguez-Zapata. 2005. Agrobacterium-mediated transformation of Musa acuminata cv. "Grand Nain" scalps by vacuum infiltration. Scientia Hort. 105:359-371

Arinaitwe, G., S. Remy, H. Strosse, R. Swennen, and L. Sagi. 2004. Agrobacterium- and particle bombardment-mediated transformation of a wide range of banana cultivars, p. 351-357. In: J.S. Mohan and R. Swennen (eds.). Banana improvement: Cellular, molecular biology, and induced mutations. Science Publishers Inc., Enfield, NH.

Becker, D.K., B. Dugdale, M.K. Smith, R.M. Harding, and J.L. Dale. 2000. Genetic transformation of Cavendish banana (Musa spp. AAA group) cv 'Grand Nain' via microprojectile bombardment. Plant Cell Rpt. 19:229-234.
Liu, J., P. Gao, X. Sun, J. Zhang, P. Sun, J. Wang, C. Jia, J. Zhang, W. Hu, B. Xu, and Z. Jin. 2017. Efficient regeneration and genetic transformation platform applicable to five Musa varieties. Electron. J. Biotechnol. 25:33-38.

May, G.D., R. Afza, H.S. Mason, A. Wiecko, F.J. Novak, and C.J. Arntzen. 1995. Generation of transgenic banana (Musa acuminata) plants via Agrobacterium-mediated transformation. Nat. Biotechnol. 13:486-492.

Maziah, M., M. Sariah, and S. Sreeramanan. 2007. Transgenic banana Rastali (AAB) with $\beta-1,3$ glucanase gene for tolerance to Fusarium wilt race 1 disease via Agrobacterium-mediated transformation system. Plant Pathol. J. 6:271282.

Murashige, T. and F. Skoog. 1962. A revised medium for the growth and bioassay with tobacco tissue culture. Physiol. Plant. 15:473-497.

Remy, S., E. Thiry, B. Coemans, S. Windelinckx, R. Swennen, and L. Sági. 2005. Improved T- 
DNA vector for tagging plant promoters via high-throughput luciferase screening. Biotechniques 38:763-770.

Rustagi, A., S. Shekhar, D. Kumar, A. Jayaswal, V. Bhat, and N.B. Sarin. 2016. Genetic fidelity of in vitro cultures of an elite Indian Musa (Aa) variety Matti. Adv. Plants Agr. Res. 4(3):292-296.

Sági, L., B. Panis, S. Remy, H. Schoofs, K.D. Smet, R. Swennen, and B.P.A. Cammue. 1995. Genetic transformation of banana and plantain (Musa spp.) via particle bombardment. Nat. Biotechnol. 13:481-485.

Sagi, L., S. Remy, B. Panis, R. Swennen, and G. Volckaert. 1994. Transient gene expression in electroporated banana (Musa spp., cv. 'Bluggoe', ABB group) protoplasts isolated from regenerable embryogenetic cell suspensions. Plant Cell Rpt. 13:262-266.
Sági, L., S. Remy, B.P. Cammue, K. Maes, T. Raemaekers, B. Panis, H. Schoofs, and R. Swennen. 2000. Production of transgenic banana and plantain. Acta Hort. 540:203-206.

Shivani and S. Tiwari. 2019. Enhanced Agrobacteriummediated transformation efficiency of banana cultivar Grand Naine by reducing oxidative stress. Scientia Hort. 246:675-685.

Southern, E.M. 1975. Detection of specific sequences among DNA fragments separated by gel electrophoresis. J. Mol. Biol. 98:503-517.

Tripathi, L., J. Tripathi, and J.A. Hughes. 2005. Agrobacterium-mediated transformation of plantain (Musa spp.) cultivar Agbagba. Afr. J. Biotechnol. 4:1378-1383.

Tripathi, L., J.N. Tripathi, and W.K. Tushemereirwe. 2008. Rapid and efficient production of transgenic East African Highland Banana (Musa spp.) using intercalary meristematic tissues. Afr. J. Biotechnol. 7:1438-1445.

Vishnevetsky, J., T.L. White, A.J. Palmateer, M. Flaishman, Y. Cohen, Y. Elad, M. Velcheva, U. Hanania, N. Sahar, and O. Dgani. 2011. Improved tolerance toward fungal diseases in transgenic Cavendish banana (Musa spp. AAA group) cv. Grand Nain. Transgenic Res. 20:61-72 .

Wei, Y.R., X.L. Huang, J. Li, X. Huang, and X.J. Li. 2005. Establishment of embryogenic cell suspension culture and plant regeneration of edible banana Musa acuminata cv. Mas (AA). Chin. J. Biotechnol. 21:58-65.

Yip, M.-K., S.-W. Lee, K.-C. Su, Y.-H. Lin, T.-Y. Chen, and T.-Y. Feng. 2011. An easy and efficient protocol in the production of transgenic banana against Fusarium wilt. Plant Biotechnol. Rpt. 5:245-254. 